\title{
Repensando as interpretações e memórias de 1968
}

Pablo Emanuel Romero Almada*

https://orcid.org/0000-0002-3729-8360

Introdução

Os anos 1960 e especialmente as manifestações sociais de 1968 têm sido um dos temas de bastante destaque na historiografia e na teoria social contemporânea. A projeção da memória de 1968 no tempo presente, tomada pelos balanços memorialísticos flagrantes nas comemorações decenais, é, portanto, o objeto do presente artigo. Parte-se de um duplo questionamento: o primeiro refere-se à tematização inicial proposta pela Teoria Social, o que posteriormente se configurou como um afastamento do interesse analítico e teórico sobre este objeto, para que, então, despertasse o interesse analítico por parte da História do Tempo Presente; o segundo diz respeito à concepção de 1968 em suas "comemorações", ou seja, entender como 1968 foi abordado nos seus respectivos aniversários, para, finalmente, lançar um olhar sobre o sentido da memória subjacente às interpretações dessa data (e do que ela representa histórica e culturalmente). Considera-se que houve mudanças nos sentidos, nas interpretações e nas análises dos acontecimentos de 1968, por parte de seus protagonistas e teóricos, sobretudo no sentido de apagamento daqueles eventos (Ross, 2002). Por isso, os resultados da pesquisa aqui apresentada questionam como essas mudanças estão presentes nas revisitações acadêmicas e na composição das memórias dos protagonistas, as quais projetam considerações individuais sobre os ocorridos e os respectivos pontos de vista das coletividades.

* Universidade Estadual Paulista Júlio de Mesquita Filho, Araraquara, São Paulo, Brasil. 
Do ponto de vista metodológico, a História do Tempo presente colocou a memória como categoria central, a partir do reconhecimento e da busca de correlações fragmentais que fazem parte de sua demarcação pela experiência (Sandoica, 2004). A relação entre história e memória apresenta o "trabalho do tempo" (Nora, 2008, p. 134), que incide sobre a história mitificada e a historiografia de reconstrução, pois a mitificação acaba pondo em risco a própria memória. A memória é o espaço de reconstrução dos eventos do passado, e sua representação evidencia o retorno ao momento comemorado, mas sob a égide das forças e dos pensamentos políticos e identitários do presente. São as ideologias, os movimentos teóricos e filosóficos além da própria conjuntura política - que guiarão os sentidos e as possibilidades de reinterpretação a partir da memória e da subjetividade. Trata-se, portanto, de reconhecer que são mobilizadas Políticas de Memória, ou seja, a memória social pela qual se busca compreender "como a sociedade interpreta e se apropria de seu passado" (Sandoica, 2004, p. 526).

No "calor dos acontecimentos", 1968 se apresentou como um objeto de reflexão das teorias sociais, influenciando sobremaneira diversas abordagens teóricas das ciências sociais, da filosofia e da história, sejam elas próximas do pensamento conservador, do marxismo ou das teorias da subjetividade (Wieviorka, 2018). Tais escritos elaboram conceitos derivados de um paradigma revolucionário, o qual interliga a teoria social e a ação política em torno do marxismo "ocidental", do estruturalismo e do pós-estruturalismo, construindo conceituações que ainda são bastante utilizáveis na compreensão macrossociológica. Porém, já nas décadas seguintes, novas concepções teóricas trouxeram, de algum modo, a reflexão de 1968 para a formulação de novas categorias analíticas. É o que acontece na década de 1980, quando a perspectiva de nova subjetividade reinterpreta aqueles acontecimentos mediante a fragmentação social e o individualismo, opondo-se ao paradigma revolucionário anterior. Na década seguinte, 1968 é majoritariamente compreendido por seu fracasso, conforme a teoria social se debruça cada vez mais na compreensão de fenômenos impulsionados pela globalização e pelo consenso político em torno das democracias liberais. Assiste-se ao florescimento do paradigma pós-moderno (Santos, 2006), o que implicou a atitude de repensar a validade das categorias da modernidade e, ao mesmo tempo, questionar a pertinência de novos paradigmas.

\section{8 e a Teoria Social Contemporânea}

O Maio de 1968 é um evento-chave para a compreensão dos desenvolvimentos sociais e políticos do século Xx. Sua importância é devidamente trabalhada na teoria social e na historiografia até hoje, fato que, desde o seu surgimento, desperta maior 
atenção de intelectuais e de cientistas sociais com as mais variadas abordagens. Os primeiros estudos produzidos "no calor dos acontecimentos" revelam importantes aspectos do campo de debate intelectual francês, o qual era praticamente dominado pela fenomenologia de Jean-Paul Sartre e pelo estruturalismo, ambos em estreito diálogo com o marxismo. Edgard Morin, Cornelius Castoriadis e Claude Lefort, em um dos primeiros balanços produzidos sobre os eventos, ressaltaram a originalidade cultural do Maio de 1968, a "brecha" que indicava a abertura de novos tempos, contrários à dominação das guerras, da sociedade de consumo e do crescimento capitalista (Morin, Lefort \& Castoriadis, 2018). Com motivações variadas, esses intelectuais lançaram um olhar sobre como as manifestações ocorriam nos campi franceses, buscando identificar a potencialidade de transformação social que estava sendo aberta, mas sem apostar em uma direção unívoca.

Na mesma linha, Henri Weber e Daniel Bensaid, na obra de 1968 intitulada Mai 68: une répétition générale, utilizaram-se de sua experiência como militantes trotskistas para afirmar que o Maio de 1968 era um indicativo de que o mundo seria mudado em direção contrária ao capitalismo (Weber, 2008). O paradigma revolucionário seria, portanto, aquele que uniria a política, a transformação social e o anticapitalismo, presentes no ensaio de 1968 e que, por conseguinte, se desenvolveria em momentos posteriores. Como a expectativa revolucionária não se concretizou, deixou em aberto algumas lacunas quanto à própria capacidade do movimento estudantil em conduzir uma revolução de modo independente da classe trabalhadora. No que lhe concerne, essa explicação se contrapõe às tensões teóricas e práticas descritas por Alain Touraine, em sua Teoria da Ação. $\mathrm{Na}$ obra La société post-industrielle, o sociólogo francês elabora a sua explicação do movimento estudantil com base na transição do modelo societal da sociedade industrial para a sociedade pós-industrial, identificando que o ator de transformação histórica da primeira, a classe operária, encontrava-se limitado e enfraquecido devido ao exercício de poder do patronato e controle fabril (Touraine, 1971). O movimento estudantil surgiria como um novo movimento social, o qual expressaria as capacidades de mudanças técnico-produtivas e o papel preponderante na produção tecnológica assumidos pelas universidades, distanciando-se também dos conflitos classistas anteriores (Waters, 2008).

Paradoxalmente, uma análise do pensamento marxista francês revela que o interesse por 1968 não decorreu especificamente do acontecimento, mas a partir das inúmeras discussões em torno das renovações do socialismo que ocorriam na Europa desde a primeira metade daquela década. Louis Althusser e parte da intelectualidade marxista francesa estiveram empenhados, desde 1966, em revitalizar o marxismo do Partido Comunista Francês (PCF) em torno de uma ciência marxista e de uma formulação teórica com maior precisão na condução das lutas de classe. Essas críticas 
influenciaram os rumos do PCF e de estudantes ligados à organização, especialmente com relação ao stalinismo, permitindo uma aceitação do maoismo pelas camadas estudantis (Capdevielle \& Ray, 2008; Levine, 2003). A postura antistalinista foi compartilhada por outras correntes políticas gestadas fora do movimento estudantil, encontrando ressonâncias e aproximações nos direcionamentos de Guy Debord e da Internacional Situacionista, as quais ensejaram o socialismo libertário e conselhista, de crítica à espetacularização cultural do capitalismo (Corrêa \& Mhereb, 2018).

Fora do meio intelectual francês, Herbert Marcuse recebeu atenção especial por parte da esquerda estudantil alemã e norte-americana com a publicação de One- dimensional man, em 1964, por causa de seu diagnóstico acerca das impossibilidades da transição na sociedade capitalista submetida à lógica totalitária (Marcuse, 1973). Nessa obra, Marcuse postulou criticamente que a tecnicidade do capitalismo havia fechado as portas para os tradicionais conflitos de classe, ao converter a técnica em um meio político de dominação. O filósofo alemão indicou um terreno fértil, embora restrito, de surgimento de "novos sujeitos emancipatórios" na esfera da estética e da arte, valorizando a ação de grupos marginalizados pelo processo produtivo, algo que se edificaria com o movimento estudantil e as lutas terceiro-mundistas alguns anos mais tarde (Marcuse, 1969, 1981; Valle, 2005). O movimento estudantil exerceria o papel de "catalisador" das lutas sociais compondo novos círculos de mobilização e de proximidade com os imigrantes, com o movimento negro, com os movimentos feministas, com as lutas por direitos políticos e civis e com os movimentos de libertação nacional e anti-imperialistas. Foram a antecipação da existência de novas forças sociais, bem como o lançamento de um olhar sobre o chamado "terceiro mundo", que trouxeram um caráter de aproximação de Marcuse com o movimento estudantil alemão e estadunidense (Katsiaficas, 1987).

Se Althusser e Marcuse obtiveram uma relação muito mais política e militante com os movimentos estudantis, as percepções de 1968 não se restringiram às formulações da teoria marxista. Filósofos e sociólogos das mais variadas correntes de pensamento - como Michel Foucault, Gilles Deleuze, Félix Guattari, Jacques Lacan e, ainda, os chamados nouveaux philosophes, como Bernard-Henri Lévi, André Glucksmann e Alain Finkielkraut - atribuíram um novo recorte em torno do acontecimento estudantil e das particularidades do caso francês. Para os nouveaux philosophes, 1968 tinha a especificidade de haver sido um momento revolucionário, que dominou os imaginários da esquerda e que nutriu sonhos em torno da emancipação, mas cujo resultado foi o contrário do esperado.

Essas leituras, centradas no caso francês, ainda que demarcadas pela heterogeneidade de escritos sociológicos e filosóficos, identificam o "pensamento 68", cuja epistemologia era a da desconstrução histórica do sujeito coletivo, ao enfatizar as 
relações de poder e a descentração do sujeito (Ferry \& Renaut, 1990). Nesse pensamento, os acontecimentos de 1968 são "propagadores da tecnocracia, uma extensão continuada da sociedade de consumo e da padronização da cultura de massa, [...] sancionando o crescimento de um individualismo hedonista, [...] um estágio para o retorno massivo da ideologia liberal em meados da década de 1970" (Starr, 1995, p. 33). Portanto, uma crítica pertinente ao chamado "pensamento 68" conduz aos limites da localidade do movimento, ou seja, da sua exclusividade ao caso francês (ou europeu), e à falta de paralelo com o restante do mundo, além da perda de sentido dos conflitos, das utopias e das ideologias da sociedade industrial.

Paralelamente, Michel Foucault percebia a exclusividade do "evento" em terras francesas, entendendo-o positivamente como "antimarxista", ou seja, contrário ao marxismo soviético, mas elucidando a relação entre corpo, linguagem e poder. Esse direcionamento mais tarde foi entendido como um dos componentes inéditos, constituintes de uma linguagem de protesto antidisciplinar, presentes não apenas nas rebeliões dos anos 1960, mas nos movimentos de contestação posteriores (Stephens, 1998). A contra-herança de 1968, como formulada por Gilles Deleuze e Félix Guattari, foi a constatação de impactos na política, na linguagem e na subjetividade, que eram projetados a partir de um capitalismo dependente de uma machine désirant, $\mathrm{e}$ sua "produção pela produção", resultando no esquizofrênico esvaziamento do sujeito (Deleuze \& Guattari, 2010).

Com o anúncio da crise de paradigmas das ciências sociais de finais da década de 1980, tornaram-se raras as reflexões teóricas sobre 1968 e, quando ocorrem, evidenciam o sintoma de um fracasso da crítica inerente aos protestos dos anos 1960. A contestação estudantil de 1968 foi vista através da crítica social ao capitalismo, evidenciando a crise do fordismo, a crítica ao consumismo e a aceitação de uma ideologia antiprodutivista e pós-materialista (Santos, 1994). Embora se questione a recusa da cidadania liberal, 1968 não indicou a construção de alicerces para a edificação da subjetividade como parte de uma nova cultura política. Por isso, foi dado que sua eficácia havia sido parcial, o que significa que nem se consolidou uma revolução, nem se consolidou uma reforma, tampouco sua gramática de conflitos é unívoca.

Em contrapartida, o mecanismo de sucesso dos movimentos de 1968 explicitou a junção de uma "crítica artística", conduzida pelos estudantes contra a opressão social, e uma "crítica social", conduzida pelos trabalhadores contra a ausência de solidariedade no capitalismo (Boltanski \& Chiapello, 2008). Essas análises reiteram que 1968 resultou na não conciliação entre os velhos e os novos sujeitos e os movimentos sociais, entre capital e trabalho, mas, sim, na disputa pelo significado em torno da complexa problemática referente aos velhos esquemas classistas. Essa foi a contribuição da formação de um "novo espírito do capitalismo" (Boltanski \& Chiapello, 
2008), em que esse sistema passou a incorporar, primeiramente, a crítica social dos trabalhadores e, posteriormente, a crítica artística dos estudantes, integrando-as à sua dinâmica de controle, de lógica produtivista e ideológica das demandas sociais.

Um balanço geral das interpretações elaboradas pela teoria social a partir dos anos 1980 sobre os protestos de 1968, apesar de sua enorme heterogeneidade, apresenta um ponto em comum: o consenso de que as suas conquistas pararam de produzir efeitos sociais e sofreram reveses nos tempos atuais. Os novos problemas sociológicos voltaram-se à compreensão do tempo presente e de novos fenômenos de mobilização social, e, sendo assim, entende-se que a Teoria Social tenha procurado redimensionar 1968 com base nas diversas vertentes expostas anteriormente.

\section{Reconstruindo 1968 a partir da memória}

O evento de 1968, por conta de sua imensa pluralidade de sentidos, foi objeto de diversas interpretações e especulações. Nos períodos de "comemoração", a cada dez anos, surgem abordagens notadamente diferenciadas com relação às precedentes. Essas “comemorações” operam um entrelaçamento interdisciplinar e, às vezes, não se filiam a nenhum sentido unívoco, tampouco surgem como consensos entre pesquisadores, intelectuais e participantes.

Na ocasião dos dez anos, a presença de 1968 sofreu do silenciamento, sendo "objeto de contracomemoração" no contexto francês, por causa da construção de uma espécie de "identidade de 68" que reduziria a pluralidade à unidade (Cardoso, 2001, p. 208). O paradigma encontrado para a interpretação dos estudos e relatos lançados ao final da década de 1970 - e que repercutem na década seguinte - remete às construções de uma observação participante, ou seja, de um relato da participação individual que contrasta a desilusão individual com a coletiva (Stephens, 1998).

No Brasil, também nesse período, 1968 ainda apresentava um impacto recente no establishment em razão do contexto político da ditadura brasileira, de tal modo que ainda havia uma escassez de estudos sobre o tema. Foi o período de publicações de antigos participantes (Gabeira, 1979; Betto, 1991), com destaque para os relatos da experiência na luta armada, os quais retrataram as táticas e ações de grupos armados, como a Aliança Libertadora Nacional (ALN) e o Movimento Revolucionário Oito de Outubro (MR-08), quase sempre endossando uma visão de orgulho com as participações, ou de um leve distanciamento crítico com os ocorridos.

Nos vinte anos, especialmente na Europa e nos Estados Unidos, as narrativas elucidaram não apenas a desilusão coletiva, mas a mistura entre o sentido nostálgico, o desnorteamento dos valores e a contraposição entre o idealismo do passado e o desalento do tempo presente (Stephens, 1998). O 1968 retomado nos anos 1980 
foi interpretado como a origem do pós-modernismo, dados o fracasso e o desencantamento da esquerda, a proliferação das classes médias e o crescimento do conservadorismo (Callinicos, 2011). Em 1988, foram combinados efeitos produzidos ao longo daquele ulterior decênio - em torno da égide neoliberal e da derrocada da União Soviética - com uma normalização ou negação do passado, simplificações ou apropriações ideológicas, fixação ou perda não reconhecível e persistência de poucos signos do passado (Cardoso, 2001).

Ao final dessa década, é dado início às publicações acadêmicas brasileiras nesse campo, permitindo um tratamento mais específico do movimento estudantil brasileiro e das relações de conflito e protesto contra a ditadura militar (Martins Filho, 1987). Não obstante, a maioria das publicações realizadas naquele momento foram escritas por ex-participantes, agora acadêmicos, focando nas experiências da luta armada e suas relações com o contexto político da ditadura e da repressão (Gorender, 1987; Reis Filho \& Moraes, 1988; Reis Filho, 1990), ou, ainda, foram resultados de pesquisas exclusivamente acadêmicas sobre a luta armada e os dilemas revolucionários da esquerda brasileira (Ridenti, 1993). O ano de 1968 também foi abordado de modo jornalístico, destacando a formação cultural e política de uma geração, cuja rebeldia foi um dos principais legados daquele "ano que não acabou" (Ventura, 2008a).

Por ocasião dos trinta anos, são percebidos dois caminhos interpretativos. $\mathrm{O}$ primeiro diz respeito à abertura global de análises que começou a ser empreendida por diversos teóricos, compondo um entendimento de interligação entre os eventos de distintos países, entre a contestação política, entre o passado e o presente, as imagens, os sonhos e fracassos revolucionários dos atores e seus ativismos políticos (De Groot, 1998; Harman, 1998). A noção de sixties também passou a ser empreendida, ao evidenciar as dinâmicas da contracultura e as insurgências político-culturais, inspiradas nos processos de insurgência terceiro-mundistas (Marwick, 1998). Esse radicalismo também foi identificado como uma linguagem antidisciplinar, que definiu os impasses políticos e culturais dos protestos e das rebelióes, oscilando entre o radicalismo dos sixties e o individualismo pós-moderno, em torno da complexa relação de recusa do passado e de aceitação dos termos da política contemporânea (Stephens, 1998).

Esses estudos trouxeram várias ampliações teóricas e comparativas. Uma delas é geopolitica, pois 1968 não foi apenas a cronologia dos eventos de Paris, mas sim um conjunto de acontecimentos espalhados pelo mundo. A temporalidade também foi algo incorporado, pois falar-se de 1968 pode ser cabível à mobilização estudantil no Brasil, ao Massacre de Tlatelolco no México, ou aos eventos da Primavera de Praga na Tchecoslováquia, e aos Incidentes de 68 na Espanha, todos no mesmo ano; ou 
ainda, o Free Speech Movement, de 1964, dos Estados Unidos, a Oposição Extraparlamentar, de 1966, na Alemanha Ocidental, o Cordobazo, de 1969, na Argentina, a Crise Acadêmica, de 1969, em Portugal.

Quanto ao Brasil, esse movimento do 1968 global não se faz sentir por completo nos delineamentos acadêmicos do tema. No que lhe concerne, há uma perspectiva aberta de estudos comparados, através de contextos como o brasileiro, o francês e o mexicano (Martins Filho, 1996), mas cuja principal preocupação são os tons e desenvolvimentos da violência do regime militar para com os estudantes e com a esquerda, em geral, tanto nos episódios mais conhecidos, como a morte do estudante Edson Luís, a Sexta-Feira Sangrenta, nos conflitos da Rua Maria Antônia e no fechamento do Xxx Congresso da Une, quanto no fechamento da UnB em Brasília (Martins Filho, 1998; Valle, 1999; Gurgel, 2002).

O segundo caminho diz respeito aos estudos memorialísticos, os quais articulam dimensões da memória coletiva e a disputa de versões, de participantes e da mídia. $\mathrm{Na}$ França, os trinta anos foram tratados a partir de uma "memória comemorativa", que atribuiu ao passado a condição de "proliferação puramente memorial” (Nora, 2008 , p. 170). Os balanços resultantes a partir daí compuseram "o formativo período de memória coletiva dos eventos de 1968”, pavimentada por uma geração de ex-participantes e a sua entrada na política institucional (Reynolds, 2011, p. 28). Percebeu-se também o "surgimento do estudante nas demonstrações de rua do período” (Mann, 2011, p. 204), realizando um resgate daquelas manifestações e da participação individual, algo que havia sido silenciado nos relatos das últimas três décadas. No entanto, a enorme quantidade de estudos e de discursos existentes resultou em um efeito contrário da retomada memorial no Maio Francês, pois a produção desses discursos foi proporcional ao efeito de "liquidar [...], apagar ou tornar obscura a história de Maio" (Ross, 2002, p. 3).

O diferencial para esse momento de composição memorialística é a participação dos meios de comunicação e da grande mídia no tratamento da memória de 1968, oferecendo interpretações outras, até mesmo concorrentes. No Brasil, os relatos de ex-líderes do movimento estudantil brasileiro, bem como a conjunção das visões de intelectuais e outros líderes de movimentos pelo mundo, de acadêmicos e jornalistas (Dirceu \& Palmeira, 1998; Garcia \& Vieira, 1999), identificaram que ainda era possível construir outras interpretações, bem como estimar que o legado de 1968 ainda estaria em disputa na formação das forças políticas, de suas aspirações e projetos para o tempo presente. O outro aspecto desses trinta anos foi denominado de "retorno midiático", conforme se postulou um confronto entre os efeitos dos acontecimentos e o poder de manipulação e de espetacularização dos eventos (Cardoso, 2001). A leitura da revista Veja incorreu nesse sentido, ao divulgar a composição ideológica 
em torno do silenciamento dos protestos estudantis. Ao enfatizar a lógica de uma revolução moral e de uma juventude transviada e perdida, o semanário valorizou aspectos específicos da contracultura, destacando os ecos da conjuntura internacional e o desmonte dos "bons costumes", sem elucidar nenhum saldo positivo (Valle, 2012, pp. 137-139). Já o jornal O Estado de S. Paulo apresentou relatos de antigos protagonistas, acentuando a temática da luta armada, com o intuito de desaboná-la ou, ainda, de ensejar relatos céticos e autocríticos, denotando o arrependimento dos participantes em relação aos efeitos políticos da luta armada, mediante sua recente entrada na política institucional e incumbência em cargos governamentais (Valle, 2018). A visão midiática reforçou os sentidos da violência, ao apresentar uma condenação dela pela opinião pública, enquanto as memórias dos participantes ressaltavam o não arrependimento e a atualidade daquelas atitudes do passado.

Os balanços dos quarenta anos demonstraram a continuidade de várias perspectivas abertas desde as últimas décadas. Destacam-se dois movimentos: um primeiro, composto pelo alargamento do 1968 global; o segundo, pela entrada do conservadorismo na disputa da memória (Scott-Smith, 2008).

O primeiro movimento, de alargamento das considerações do 1968 global, ressalta as vertentes da história transnacional de protestos, que deu relevo às análises comparativas entre os países e às circulações de ideias e movimentos transfronteiriços. Essa perspectiva se coadunou com paradigmas epistemológicos mais recentes, como o feminismo e o pós-colonialismo. Sobressai o questionamento quanto a 1968 ter sido um momento de projeção da imagem da racionalidade ocidental, que abafaria o surgimento de novas perspectivas pós-coloniais de alteridade (descentradas da narrativa universalista ocidental) e que enunciaria também a presença de outros atores, como o movimento feminista e de mulheres negras, além da significativa presença dessa contestação em outros espaços descentrados do contexto europeu (Bhambra \& Demir, 2009). Dado o alargamento espacial dessas relações trans-históricas, é preciso também questionar como os novos conflitos revolucionários do mundo contemporâneo, como a Primavera Árabe, não aferem os limites das perspectivas críticas de transformação social, almejados pelo Ocidente e dos quais 1968 é o seu principal representante contemporâneo (Pawling, 2013). Essas interpretações instigam a pesquisa social para transpor os limites da modernidade ocidental, já que 1968 pode conter ambivalências não apenas na construção de seu discurso analítico, mas também na projeção imagética da representação do Ocidente e de sua crítica social.

O segundo movimento elucida as respostas conservadoras e revisionistas sobre 1968, em específico ao Maio Francês, conforme o argumento de rebelião social passa a ser mantido sob suspeição ou, então, profundamente questionado. Assim, em termos gerais, concebeu-se a culpabilidade do fracasso de 1968 por parte de seus 
próprios atores, insinuando que as coisas poderiam ter sido diferentes e que, devido à "negligência da militância laboral", houve o fracasso e a derrota da rebelião de 1968 (Mann, 2011, p. 204).

Porém, o principal ataque conservador a 1968 esteve nas eleições francesas de 2007, quando Nicolas Sarkozy clamou pela liquidação da herança de 1968. O surgimento de um pensamento anti-68 vinha se erigindo no contexto francês, visando a atacar algumas das consequências posteriores à data, como a presença significativa da esquerda nos campos universitários e no domínio do debate público (Gordon, 2008). Esse é um efeito que elucida como o passado foi percebido, reivindicado e manipulado pelo presente, dada a capacidade de perpetuação de 1968 na memória. Em torno disso, construiu-se uma espécie de "história oficial", que passou a dominar algumas das representações e que, ao longo das comemorações decimais, teve o seu sentido progressivamente reduzido (Reynolds, 2011, p. 12). Essa redução esteve presente na descrição de que a violência seria apenas simbólica, de que as ações poderiam ser reduzidas aos slogans, de que as consequências estariam limitadas às áreas específicas do feminismo, da ecologia, da moral e dos avanços culturais, e, ainda, geralmente, essa perspectiva redutora surge também no Maio Francês, que aparece diluído, mutilado, mitologizado, abandonando sua perspectiva histórica (Reynolds, 2011, p. 13).

No Brasil, os quarenta anos apresentaram, por um lado, menor influência dos paradigmas anteriormente descritos, e, por outro, descreveram um contexto ainda mais complexo de silenciamentos projetados pela violência da ditadura militar, os quais encontram nas universidades um local de constante vigilância e significativa ação das forças repressivas (Motta, 2014). Destacam-se as narrativas de outros personagens cujas memórias ainda não haviam sido revisitadas (Meloni, 2009) ou, ainda, a compreensão das temáticas acerca do sentido das memórias, a partir de estudos acadêmicos e da abordagem de novos contextos pelo Brasil (Zaidan Filho \& Machado, 2007; Fico \& Araújo, 2009), bem como, finalmente, os aportes globais da revolta estudantil e seus efeitos na articulação de lutas sociais (Groppo, 2005; 2008). Do ponto de vista jornalístico, a temática do destino das gerações e de seus possíveis sucessos e/ou fracassos também esteve presente no debate, ao se observarem as trajetórias biográficas desses personagens, mas, do ponto de vista do tempo presente, suscitando-lhes um balanço memorialístico, o qual raramente é dado por ressentimentos, elaborando-se muito mais pela construção de um orgulho, por um não arrependimento, ainda que mantida certa distância para com as ideologias e as práticas implementadas anteriormente (Ventura, 2008b). A mídia tradicional, ao referenciar os quarenta anos de 1968, também se direcionava para um caminho semelhante, de acordo com os ideais de justiça social, condicionados a resultados 
políticos e econômicos satisfatórios. Para tanto, dever-se-ia afastar o ideário político de 1968, compondo um discurso conservador e cético frente às transformações sociais e aos efeitos positivos da contestação (Valle, 2012).

\section{Os cinquenta anos e as suas possibilidades interpretativas}

Como compreendido até aqui, a pluralidade de explicações sobre 1968 pode ser percebida de modo diacrônico, tanto referenciando as leituras que se sobressaem, quanto tomando os paradigmas e análises acadêmicas do contexto francês e brasileiro. Conforme mudam as abordagens de 1968, aqueles acontecimentos passam a ser muito mais ambivalentes e incertos do que outrora, pois, paradoxalmente, há maior complexidade de contextos, de causalidades e de implicações espaciotemporais, do mesmo modo que os acontecimentos são reduzidos e mitificados de acordo com a conveniência das partes interessadas. A disputa de sentidos que o acontecimento produz, portanto, está longe de uma resolução unívoca, mas conduz a pesquisa por investigar como essas disputas podem ser dadas no presente momento, ou seja, observando o período da comemoração dos cinquenta anos.

No caso do Brasil, uma primeira abordagem pode ser construída a partir da análise bibliográfica acerca de obras publicadas (livros) em 2018 sobre 1968 , em um recorte ainda preliminar. Descartadas as obras republicadas, a gama de livros é menor que no decênio anterior, ainda que haja maior presença de autores devido aos livros produzidos sob o formato de coletânea. Ressalta-se também a prevalência de estudos de acadêmicos e intérpretes em detrimento de depoimentos ou versões de ex-protagonistas: visto que a idade dos protagonistas já se encontra elevada ou que muitos destes já não estão mais vivos, estariam os intérpretes tomando o lugar dos protagonistas? A pesquisa empreendida nesse campo demonstra que os estudos acadêmicos têm incorporado grande parte da visão dos protagonistas, oferecendo modelos interpretativos pouco descolados daqueles oferecidos pelos protagonistas.

Esse pequeno descolamento não significa o apagamento da participação dos ex-protagonistas. A principal característica dos escritos sobre 1968 em seus cinquenta anos é a consolidação das pesquisas nas áreas de História e Ciências Sociais, de modo que as visões de intelectuais e de ex-participantes se aproximam e se combinam, criando uma espécie de consenso em torno da importância de 1968 em oposição à ditadura militar (Miranda et al., 2018; Nunes et al., 2018; Muller, 2018). No

1. O levantamento dessa bibliografia foi possível graças ao projeto "Protagonistas e Intérpretes de 1968: Silenciamento, Ocultamento e Memória”, financiado pela Fapesp (n. 2017/18171-7) e coordenado pela profa. dra. Maria Ribeiro do Valle, Unesp - FCLAR. 
entanto, a noção de oposição ganha novos contornos. Primeiramente, como parte das pesquisas aborda contextos e conjunturas locais que estão descentralizadas do eixo Rio-São Paulo, pelo qual os primeiros estudos se pautaram, amplia-se também a percepção de que não somente a resistência estudantil esteve espalhada por todo o Brasil, como a própria violência do regime militar não foi nada pontual, mas, sim, sistemática, presente nas capitais e nos interiores.

Em segundo lugar, reforça-se a percepção de que o movimento estudantil não foi o único ator a se mobilizar contra a ditadura, mas que talvez tenha sido aquele que ganhou maior impacto, maior destaque por conta de seus episódios e pela espetacularização das ações de contenção das forças repressivas. O movimento dos trabalhadores, naquele ano, vivenciou greves importantes, de Osasco e Contagem, que em muito haviam sido minimizadas pelas pesquisas sociais, as quais acabaram por enfatizar o maior impacto das ações estudantis, bem como observaram o movimento sindical existente - antes do "novo sindicalismo" de finais da década de 1970 - como imaturo ou, ainda, cooptado, segundo a tradição varguista, pelas forças políticas dominantes.

Em terceiro lugar, ressalta-se que o movimento estudantil universitário possuía diversas imbricações com o movimento estudantil secundarista, fluxo não restrito apenas às suas lideranças. Embora isso significasse que os movimentos estivessem juntos em algumas ações políticas, não havia uma unidade entre eles, nem qualquer plano de ação definido em conjunto. Destaca-se a problematização das fronteiras entre os movimentos estudantis, em suas facetas universitária e secundarista, e o movimento operário, evidenciando trânsitos e porosidades no interior dos movimentos, os quais permitem a existência de identidades políticas individuais pouco rígidas.

Essas características também são notadas quanto aos personagens e atores políticos e às suas respectivas organizações. A UNE aparece cada vez mais ao lado de um conjunto bastante complexo de grupos e organizações políticas, sejam elas de esquerda, sejam elas originadas nas juventudes progressistas da Igreja Católica. Se, até os trinta anos de 1968, a relação entre os estudantes e a militância política organizativa da UNE era um dado bastante explorado, nota-se que a trajetória posterior dos estudantes - em direção à luta armada e à composição participativa em organizações políticas - tem mantido sua relevância para as análises. Isso reforça o debate em torno das questões do silenciamento sofrido pelos movimentos estudantis, de modo que, encerrado o principal canal de participação política, a UNE, e estabelecido o AI-5, as capacidades efetivas de mobilização se evanesceram para os próximos anos.

Do mesmo modo, os grupos da luta armada não são retratados como protagonistas do período, tal como a literatura do primeiro decênio comemorativo parecia sugerir. No entanto, a temática da luta armada ainda permite que sejam abordados aspectos até então pouco mencionados, como a participação das mulheres naquelas 
organizações, revelando componentes de identidade de gênero naqueles movimentos (Ribeiro, 2018). Sendo um campo de pesquisa ainda carente de dados sistemáticos e, ao mesmo tempo, em vigoroso processo de expansão, a relação entre as mulheres e os movimentos de 1968 é algo que diz respeito à memória, mas, consequentemente, também se afirma como uma problemática interseccional e, ao mesmo tempo, como um tema da disciplina histórica, justamente pela influência das atuais epistemologias feministas na construção de objetos de pesquisa das ciências sociais e humanas.

O olhar acadêmico tende a encontrar outros espaços de conflitos, que fogem daqueles já consagrados pelas biografias dos ex-participantes, elucidando a perspectiva de que novas interações entre o local e o global ainda estão por se construir, sobretudo, demarcando fluxos de pessoas, de ideias e de ações coletivas. Embora a incorporação da memória pela disciplina histórica esteja presente nas composições acadêmicas, a construção das memórias dos próprios protagonistas é um fato que ainda comporta novos desenvolvimentos, dado o seu caráter rizomático e, ao mesmo tempo, pulverizado. Um exemplo disso pode ser estabelecido conforme se analisam duas autobiografias recém-lançadas, uma com um olhar sobre o Brasil e outra com um olhar sobre a França: a de José Dirceu (2018), ex-protagonista do movimento estudantil de 1968 e, posteriormente, político vinculado ao Partido dos Trabalhadores; e a de Anne Wiazemsky (2018), atriz que participou de diversos filmes de Jean-Luc Godard.

A autobiografia de José Dirceu compõe um quadro, já conhecido e explorado anteriormente (Dirceu \& Palmeira, 1998), que relata a experiência política daqueles movimentos, bem como as formas de repressão, as prisões, a clandestinidade e o silenciamento dos anos posteriores. No entanto, sua trajetória biográfica, para além de 1968, também pode ser lida como uma carta de defesa de uma narrativa de projeto político que se transmutou, com subsequentes ressalvas, a um projeto de poder dos governos do PT, o que gerou diversos desagrados com a burguesia interna e com setores das classes dominantes do Brasil. No contexto de crise e desabono desse projeto, e dados os possíveis envolvimentos do partido e de Dirceu com episódios de corrupção, como o Mensalão e a Lava-Jato, as memórias podem ser interpretadas como uma carta de defesa de Dirceu para consigo mesmo, com sua trajetória e seus ideais políticos, os quais constituem elementos importantes da memória e da identidade política da esquerda brasileira. A preocupação da escrita memorial de Dirceu, portanto, é transpassada conjunturalmente, ao afirmar que alguns acontecimentos recentes como as suas prisões, o impeachment da ex-Presidenta Dilma Rousseff, a prisão do ex-Presidente Lula, bem como a crise e a "criminalização" do PT, "além de destruir a obra e o legado de nossa geração, [...] tudo isso me obrigou a mergulhar de cabeça no meu passado" (Dirceu, 2018, p. 29). A produção memorialística 
compõe um quadro de contraposição às visões sociais formadas no tempo presente, elucidando, além do resgate memorialístico, a compreensão de que as identidades do presente - em especial da esquerda brasileira - dependem do reconhecimento dos fatos passados para consolidar a sua legitimidade.

De modo oposto ao de Dirceu, outras biografias também revelaram sentidos não usuais de 1968, como a atenção às memórias femininas e individuais sobre o Maio Francês, traço patente na obra da atriz e escritora Anne Wiazemsky (2018). Como uma voz dissonante no campo dos movimentos franceses, Wiazemsky dissocia-se do papel de "musa" da nouvelle vague e de esposa de Godard, para assumir a visão de uma participante incomum, que, apesar de estar em contato direto com os estudantes, não participava efetivamente desse espaço. Essa composição memorialística aponta uma controvérsia em torno dos limites, já tão porosos, entre a participação nos acontecimentos e o posicionamento de mero espectador, cuja ambiguidade enunciativa, como já referido, prende-se às condicionantes temporais, culturais, ideológicas e identitárias sobre as quais se erigiu a voz da escritora. Isso não ocorre quando se trata de memórias de antigos participantes, os quais, em sua maioria, apresentam a visão "por dentro" do movimento. As memórias desses participantes - em muitas vezes - são as de homens, militantes políticos, delegando à fala e à participação feminina um espaço marginal. As memórias de Wiazemsky apresentam a reconstrução cronológica dos acontecimentos do Maio Francês, mas também elucidam a discussão do ambiente intelectual e cinematográfico de Paris, as percepções do casal sobre os acontecimentos e especulam mesmo sobre o momento que estaria sendo aberto na história.

Essa projeção memorialística também deve ser percebida de acordo com o contexto francês atual (bem como de muitos outros países), no qual o protagonismo das mulheres nas lutas sociais tem se referido à denúncia do feminicídio, das violências física e simbólica sofridas no cotidiano, da suspensão dos direitos das mulheres e das desigualdades salariais. Em 2018, no Brasil, protestos como o \#elenão, o maior protesto de mulheres da história, ocorrido contra a eleição do atual presidente Jair Bolsonaro, revelam a importância da construção das memórias femininas (em suas idiossincrasias) e feministas (em sua perspectiva de mundo), as quais redimensionam tanto o protagonismo feminino quanto as identidades políticas do tempo presente a partir das experiências do passado, que se inscreveram no corpo.

\section{Conclusão}

As interpretações de 1968 ao longo de cinquenta anos, como se observa, são conflitantes, passíveis de alterações, de disputas e de novas incorporações teóricas e 
empíricas. Isso ocorre não apenas por conta de seus biógrafos e pelo interesse de acadêmicos movidos por teorias e paradigmas que regem esse campo, mas também porque se trata de uma Política de Memória, de acordo com a qual a sociedade compreende e interpreta o seu passado à luz do presente. Estimar que a memória sobre 1968 se transforma é também estimar que os próprios ocorridos escapam de categorias fixas e totalizantes, as quais, ao não serem concretizadas, entram em crise conforme questionam a realidade social da qual são provenientes. Com os avanços das agendas de pesquisa sobre o tema, principalmente dos estudos de memória, 1968 desconecta-se parcialmente das expressões de rebeliões sociais, como o Maio Francês: estabelece-se como um conceito mutável e historicamente percebido de acordo com i) as condicionantes ideológicas do presente e, por contiguidade, ii) conforme os sentidos memorialísticos construídos pelas comemorações decenais.

Os quarenta e os cinquenta anos de 1968 aparentam tornar esse fenômeno muito mais plural, com a participação de diversos atores, além dos estudantes. Isso significa que movimentos de mulheres, movimentos negros, movimentos de libertação colonial, entre outros, passam a fazer parte de um mesmo cenário político, com origens em comum e que compartilham visões de oposição às forças dominantes. Com isso, o desenvolvimento de identidades políticas é um fato que, dado de modo muito mais plural, combina diversas perspectivas em seu interior, cuja principal característica deve ser agregativa/unificadora e não exclusivista. Essa composição de saberes e visões de mundo pode ter outrora se alinhado a uma perspectiva anticapitalista e terceiro-mundista. A atualidade desses elementos não cessa com as ofensivas neoliberais e conservadoras, apesar do potencial que essas iniciativas têm para enfraquecê-los. Do mesmo modo, as produções acadêmicas tentam recriar essa conexão, indicando que é possível acessar o passado e que, quando esse acesso se concretiza, diversas perspectivas - em comum ou em desacordo - também são acessadas, reforçando a ideia de que o silenciamento também pode ser rompido, razão por que 1968 passa a ser visto pelas diversas interpretaçôes que ainda o colocam como um ponto de interrogação da história e das memórias individual e coletiva. 


\section{Referências Bibliográficas}

Betto, Frei. (1991), Batismo de sangue: os dominicanos e a morte de Carlos Marighella. Rio de Janeiro, Bertrand Brasil.

Bhambra, Gurminder \& Demir, Ipek (ed.). (2009), 1968 in retrospect: History, theory, alterity. Nova York, Palgrave Macmillan.

Boltanski, Luc \& Chiapello, Ève. (2008), O novo espirito do capitalismo. São Paulo, Martins Fontes.

Callinicos, Alex. (2011), Contra el posmodernismo. Buenos Aires, Ediciones RYR.

Capdevielle, Jacques \& Ray, Henri (dir.). (2008), Dictionnaire de Mai 68. Paris, Larousse.

Cardoso, Irene. (2001), Para uma crítica do presente. São Paulo, Editora 34.

CorrêA, Erick \& Mhereb, Maria. (orgs.). (2018), 68: Como incendiar um país. São Paulo, Veneta.

De Groot, Gerard. (1998), Student protest: The Sixties and after. Londres, Routledge.

Deleuze, Gilles \& Guattari, Félix. (2010), O Anti-Édipo: Capitalismo e esquizofrenia. São Paulo, Edições 34 .

Dirceu, José. (2018), Zé Dirceu: memórias. São Paulo, Geração Editorial.

Dirceu, José \& Palmeira, Vladmir. (1998), Abaixo a ditadura: o movimento de 68 contado por seus líderes. São Paulo, Garamond.

Ferry, Luc \& Renaut, Alain. (1990), French philosophy of the Sixties: Essay on antihumanism. Massachusetts, The University of Massachusetts Press.

Fico, Carlos \& Araújo, Maria Paula (orgs.). (2009), 1968, 40 anos depois: história e memória. Rio de Janeiro, 7Letras.

Gabeira, Fernando. (1979), O que é isso companheiro? Rio de Janeiro, Codecri.

Garcia, Marco Aurélio \& Vieira, Maria Alice (orgs.). (1999), Rebeldes e contestadores: 1968 : Brasil, França e Alemanha. São Paulo, Fundação Perseu Abramo.

Gordon, Daniel. A. (2008), “Liquidating May '68? generational trajectories of the 2007 presidential candidates". Modern \& Contemporary France, 16 (2): 143-159.

GoRENDER, Jacob. (1987), Combate nas trevas: a esquerda brasileira: das ilusões perdidas a luta armada. São Paulo, Ática.

Groppo, Luís Antônio. (2008), 1968: retratos da revolta estudantil no Brasil e no mundo. Piracicaba, Biscalchin.

Groppo, Luís Antônio. (2005), Uma onda mundial de revoltas: Movimentos estudantis de 1968. Piracicaba, Editora Unimep.

Gurgel, Antônio de Pádua. (2002), A rebelião dos estudantes: Brasilia, 1968. Brasília, unB.

Harman, Chris. (1998), The fire last time: 1968 and after. Londres, Bookmarks.

KatsiafiCAs, Georgy. (1987), The imagination of the new left: a global analysis of 1968. Boston, South End. 
Levine, Andrew. (2003), A future for Marxism? Althusser, the analytical turn and the revival of Socialist Theory. Londres, Pluto Press.

Mann, Keith. (2011), "A revival of labor and social protest research in France: Recent scholarship on May 1968". International Labor and Working-Class History, 80 (1): 203-214.

Marcuse, Herbert. (1973), A ideologia da sociedade industrial: O homem unidimensional. Rio de Janeiro, Zahar Editores.

Marcuse, Herbert. (1981), Contrarrevolução e revolta. Rio de Janeiro, Zahar Editores.

Marcuse, Herbert. (1969), O fim da utopia. Rio de Janeiro, Paz e Terra.

Martins Filho, João Roberto (org.). (1998), 1968: Faz 30 anos: os estudantes contra a ditadura. São Paulo, Fapesp.

Martins Filho, João Roberto. (1996), A rebelião estudantil: México, França, Brasil: 1968. Campinas, Mercado de Letras.

Martins Filho, João Roberto. (1987), Movimento estudantil e ditadura militar: 1964-1968. Campinas, Papirus.

Marwick, Arthur. (1998), The Sixties: Cultural Revolution in Britain, France, Italy, and the United States (1958-1974). Oxford, Oxford University.

Meloni, Catarina. (2009), 1968: o tempo das escolhas. São Paulo, Nova Alexandria.

Miranda, Danilo et al. (2018), 1968: Reflexos e reflexões. São Paulo, Editora Sesc.

Morin, Edgar; Lefort, Claude \& Castoriadis, Cornelius. (2018), Maio de 1968: A brecha. São Paulo, Autonomia Literária.

MotтA, Rodrigo Patto Sá. (2014), As universidades e o regime militar: cultura politica brasileira e modernização autoritária. Rio de Janeiro, Zahar.

Muller, Angélica (org.). (2018), 1968 em Movimento. Rio de Janeiro, Editora FGV.

Nora, Pierre. (2008), Pierre Nora en Les lieux de mémoire. Montevidéu, Ediciones Trilce.

Nunes, Paulo; Peti, Peret \& Lohn, Reinaldo (org.). (2018), Utopia e repressão: 1968 no Brasil. Salvador: Sagga Editora.

Pawling, Christopher. (2013), Critical theory and political engagement: From May'68 to the Arab Spring. Nova York, Palgrave Macmillan.

Reynolds, Chris. (2011), Memories of May'68: France's convenient consensus. Cardiff, University of Wales Press.

ReIs Filho, Daniel Aarão. (1990), A revolução faltou ao encontro: os comunistas no Brasil. São Paulo, Brasiliense.

Reis Filho, Daniel Aarão \& Moraes, Pedro de. (1988), 1968: A paixão de uma utopia. Rio de Janeiro, Espaço e Tempo.

Ribeiro, Maria Cláudia Badan. (2018), Mulheres na luta armada: Protagonismo feminino na ALN (Ação Libertadora Nacional). São Paulo, Alameda Editorial.

Ridenti, Marcelo. (1993), O fantasma da revolução brasileira. São Paulo, Editora Unesp.

Ross, Kristin. (2002), May'68 and its afterlives. Chicago, University of Chicago Press. 
Sandoica, Elena Hernández. (2004), Tendencias historiográficas actuales: Escribir Historia hoy. Madri, Ediciones Akal.

Santos, Boaventura de Sousa. (1994), Pela mão de Alice: O social e o politico na pós-modernidade. Porto, Afrontamento.

Santos, Boaventura de Sousa. (2006), A gramática do tempo. Para uma nova cultura política. São Paulo, Cortez.

Sсотт-Sмiтн, Giles. (2008), “We are all undesirables: May 68 and its legacy”. European Journal of American Studies, 3 (2): 1-5.

STARR, Peter. (1995), Logics of failed revolt: French theory after May'68. Stanford, Stanford University Press, 1995.

Stephens, Julie. (1998), Anti-disciplinary protest: sixties radicalism and postmodernism. Cambridge, Cambridge University Press.

Touraine, Alain. (1971), A sociedade post-industrial. Lisboa, Moraes.

VAlle, Maria Ribeiro do. (1999), 1968: O diálogo é a violência. Campinas, Editora Unicamp.

VAlle, Maria Ribeiro do. (2012), "1968-2008: O Veja way of life". Intercom: RBCC, 35 (2): 129-147. Disponível em http://www.scielo.br/scielo.php?script=sci_arttext\&pid=S1809$-58442012000200007 \& \operatorname{lng}=\mathrm{en} \& \mathrm{nrm}=\mathrm{iso}$.

VAlle, Maria Ribeiro do. (2005), A violência revolucionária em Hannah Arendt e Herbert Marcuse: Raizes e polarizações. São Paulo, Editora Unesp.

Valle, Maria Ribeiro do. (2018), "Quem te viu, quem te vê: O Estado de S. Paulo e 1968, 30 anos depois. In: Muller, Angélica (coord.). 1968 em Movimento. Rio de Janeiro, FGV Editora, pp.157-180.

Ventura, Zuenir. (2008a), 1968: O ano que não terminou. São Paulo, Planeta.

Ventura, Zuenir. (2008b), 1968: O que fizemos de nós. São Paulo, Planeta.

WATERS, Sarah. (2008), "Situating movements historically: May 1968, Alain Touraine, and new social movement theory”. Mobilization: The International Qharterly, 13: 63- 82.

Weber, Henri. (2008), “Um balanço de 1968”. In: Garcia, Marco Aurélio \& Vieira, Maria Alice (org.). Rebeldes e contestadores. 1968. Brasil, França e Alemanha. São Paulo, Fundação Perseu Abramo, pp. 21-26.

Wiazemsky, Anne. (2018), Um ano depois. São Paulo, Todavia.

Wieviorka, Michel. (2018), "Mayo de 1968 y las ciencias humanas y sociales”. Revista Mexicana de Ciencias Politicas y Sociales, 63 (234): 53-66.

Zaidan Filho, Michel \& Machado, Otávio (orgs.). (2007), Movimento estudantil brasileiro e a educação superior. Recife, Editora Universitária UFPE. 


\section{Resumo}

Repensando as interpretações e memórias de 1968

O artigo analisa como as interpretações e as memórias dos acontecimentos de 1968 se transformam ao longo de suas comemorações decimais. Respalda-se na análise qualitativa da História do Tempo Presente, abordando as Políticas de Memória em torno dos sentidos que aqueles eventos foram ganhando ao longo de seus cinquenta anos, tanto por parte de seus intérpretes quanto pelos protagonistas. Argumenta-se que a ampla gama de estudos valorizou seus sujeitos e conflitos, abrindo um enorme leque de interpretações, as quais guiam 1968 pelo tempo presente, renovando as suas memórias. Conclui-se discutindo algumas linhas memorialísticas em torno dos atores coletivos e de novos relatos de protagonistas, que permitem reinterpretações de 1968, em seus cinquenta anos, elucidando o seu diálogo com as atuais identidades políticas.

Palavras-chave: 1968; Movimento estudantil; Resistência; Políticas de Memória; Identidades políticas.

\section{Abstract}

\section{Rethinking the interpretations and memories of 1968}

The article analyzes how the interpretations and memories of the events of 1968 are transformed during their decimal celebrations. It is based on the qualitative analysis of the History of the Present Time, addressing the Memory Policies around the meanings that those events have gained over its 50 years, both by its interpreters and by the protagonists. It is argued that the wide range of studies valued their subjects and conflicts, opening a huge range of interpretations, which guide 1968 through the present time, renewing their memories. It concludes by discussing memorialist lines on collective actors and new reports by protagonists, which allow reinterpretations of 1968, in its fifties, explaining its dialogue with current political identities. Keywords: 1968; Students Movement; Resistance; Politics of Memory; Political identities.

Texto recebido em 17/4/2020 e aprovado em 16/9/2020.

DOI: 10.11606/0103-2070.ts.2021.168872.

Pablo Emanuel Romero Almada é pesquisador de pós-doutorado pelo Programa de Pós-Graduação em Ciências Sociais da Faculdade de Ciências e Letras de Araraquara da Universidade Estadual Paulista (FCLAR-Unesp). Doutor em Democracia no Século XXI (2015) pela Faculdade de Economia da Universidade de Coimbra (Feuc).E-mail: pabloera@gmail.com. 